\title{
Mediação escolar: a análise qualitativa da dimensão interpessoal/ social de um projeto de intervenção numa escola TEIP
}

Elisabete Pinto da Costa, Juan Carlos Torrego \& Alcina de Oliveira Martins

Resumo:

A mediação escolar configura perspetivas alargadas de intervenção para a melhoria pessoal e social dos sujeitos nos seus contextos. Tendo por base o estudo de um Projeto de Mediação de Conflitos (PMC), implementado numa Escola Básica, do centro de Portugal, visa-se analisar o impacto da intervenção pelo projeto, nos alunos e professores que participaram no mesmo, indagando os efeitos e os benefícios ao nível das relações interpessoais e na convivência escolar. Na pesquisa levou-se a cabo uma investigação qualitativa, que privilegiou as representações, os significados e as práticas em torno do PMC. Os resultados apontam para a eficácia do projeto, quanto à formação de habilidades sociais, à prevenção e resolução de conflitos e à promoção do clima relacional assente no desenvolvimento de valores e princípios e de ações essenciais à melhoria social da escola.

Palavras-chave:

mediação escolar; projeto de intervenção; dimensão interpessoal/social; investigação qualitativa. 


\title{
School mediation: a qualitative analysis of the interpersonal/social dimension of an intervention project in a TEIP school
}

\begin{abstract}
The school mediation configures broad perspectives of intervention for the personal and social improvement of people in their contexts. Based on the study of a Conflict Mediation Project (PMC), implemented in a Basic School, in the central of Portugal, the objective is to analyze the impact of the project intervention on the students and teachers, who participated in the project, and question the effects and benefits on interpersonal relations and in school coexistence. In the research a qualitative investigation was carried out, that privileged the representations, the meanings and the practices around the PMC. The results point to the effectiveness of the project, regarding the formation of social skills, the prevention and resolution of conflicts and the improvement of the relationship climate, develops values, principles and actions essentials to the social improvement of the school.
\end{abstract}

Keywords: school mediation; intervention project ; interpersonal dimension ; social dimension; qualitative research.

\section{Médiation scolaire: I'analyse qualitative de la dimension interpersonnelle/ sociale d'un projet d'intervention dans une école TEIP}

Résumé: La médiation scolaire ouvre des perspectives élargies d'intervention pour améliorer personnelle et sociale des sujets dans leurs contextes. Ayant pour base l'étude d'un projet de médiation de conflits (PMC) implanté dans une école basique, du centre du Portugal, dans le but d'analyser límpact de cette intervention pour le projet, nos élèves et professeurs qui ont participé activement dans celui-ci, curieux des effets et des bénéfices au niveau des relations entre les personnes et sur l'ambiance scolaire. Dans la recherche, une enquête qualitative favorisera les représentations, les significations et les pratiques autour du PMC. Les résultats pointent l'efficacité du projet, quant à la formation d'aptitudes sociales, la prévention et résolution de conflit, ainsi que l'évolution du climat relationnel basé sur le développement des valeurs et des principes et des actions essentielles à l'amélioration sociale de l'école.

Mots-clés: médiation scolaire; projet d'intervention ; dimension interpersonnelle/sociale; recherche qualitative.

\section{Mediación escolar: el análisis cualitativo de la dimensión interpersonal / social de un proyecto de intervención en una escuela TEIP}

Resumen: La mediación escolar configura perspectivas amplias de intervención para la mejora personal y social de los sujetos en sus contextos. Basándose en el estudio de un Proyecto de Mediación de Conflictos (PMC), que se implementó en una Escuela Básica, en el centro de Portugal, tenemos como objetivo analizar el impacto de la intervención por parte del proyecto, en los estudiantes y profesores que participaron en él, cuestionando los efectos y los beneficios a nivel de las relaciones interpersonales y en la convivencia escolar. En la investigación se llevó a cabo una investigación cualitativa, que privilegió las representaciones, los significados y las prácticas en torno al PMC. Los resultados apuntan la eficacia del proyecto, en cuanto a la formación de habilidades sociales, a la prevención y resolución de conflictos ya la promoción del clima relacional, basada en el desarrollo de valores y principios y de acciones esenciales para la mejora social de la escuela.

Palabras clave: mediación escolar; proyecto de intervención; dimensión interpersonal/social; investigación cualitativa. 


\section{Introdução}

O presente artigo centra-se num Projeto de Mediação de Conflitos (PMC) implementado numa Escola Básica de $2^{\circ}$ e $3^{\circ}$ ciclos, da zona centro de Portugal, considerada Território Educativo de Intervenção Prioritária (TEIP), num período longitudinal. Nos PMC podem definir-se três dimensões de sustentação: i) dimensão processual, que se refere ao processo e ao produto da implementação do projeto PMC. Trata-se de cuidar da mecânica e da dinâmica do modelo padrão de intervenção; ii) dimensão interpessoal/social, que se reporta à aprendizagem e à aquisição de competências de mediação, assim como à criação de figuras mediadoras e ao funcionamento de estruturas de mediação, com vista a promover atitudes e comportamentos favoráveis a uma convivência cidadã. Relaciona-se a aprendizagem dos princípios, valores e habilidades pelos indivíduos, formados em mediação e integrados nas estruturas de mediação, com o crescimento e o desenvolvimento pessoal, e, consequentemente, com a melhoria do contexto relacional e social escolar; iii) dimensão organizacional, relativa às condições institucionais necessárias para o bom funcionamento das estruturas e processos de mediação, e, sobretudo, à integração da mediação na estrutura formal da escola, que a legitima e lhe confere reconhecimento, através de normas, procedimentos e práticas que se pretendem enraizados nos sujeitos e na cultura. Mais do que aplicar um método, usar uma técnica ou criar estruturas de gestão e resolução colaborativa de conflitos, o PMC deve assumir-se como uma tecnologia social de meIhoria socioeducativa.

Para este artigo foca-se a dimensão interpessoal/social do projeto, visando-se saber quais as mais-valias da sua implementação em contexto escolar. Para o efeito, considera-se adequado um estudo qualitativo, assente em processos compreensivos da realidade, através das representações, dos significados, das crenças e das práticas em torno do PMC na dimensão identificada.

\section{Os desafios da mediação escolar implementada pela metodologia de projeto}

A necessidade de fomentar a convivência, pela gestão positiva das relações interpessoais e dos conflitos, tornou-se uma prioridade da escola. Esta dimensão social assume-se também como uma questão educativa, pedagógica e organizacional.

A socialização em contexto escolar resulta do esforço de apropriação de regras de comportamento, sendo que a articulação das normas, dos valores e dos saberes adquiridos deve refletir-se na vida social. Contudo, as dissensões e as ruturas relacionais, que se revelam nos índices de indisciplina, de conflitualidade e de violência, 
constituem tanto uma fratura à normatividade escolar, como colocam em causa a cultura disciplinar, que se espera que aí exista (Quaresma, 2010).

Neste contexto, a mediação configura perspetivas alargadas de intervenção para a melhoria pessoal e social dos sujeitos, nos seus contextos socioeducativos, promovendo novas formas de sociabilidade e de (re)construção de laços interpessoais.

O termo mediação escolar reporta-se genericamente à mediação de conflitos na escola (Torrego, 2006, Pinto da Costa, 2010, Bonafé-Schmitt, 2014), reconhecendo-se aí outros tipos de mediação - sociopedagógica, socioeducativa e sociocultural que visam dar resposta às tensões e dissensões sentidas na e pela instituição.

A mediação de conflitos foca-se nas relações interpessoais, prosseguindo como objetivo principal o (re)estabelecimento de interações sociais. Esta mediação não ocorre simplesmente para responder a conflitos existentes na escola, mas assume-se como um processo de promoção da convivência cidadã, segundo diversas lógicas: resolutiva, reparadora, educativa, preventiva e inclusiva.

No contexto escolar, a mediação é reconhecida como uma metodologia com forte potencial educativo e capacitador, e como área a explorar para a formação de competências sociais basilares para a vida em comunidade, proporcionando um universo de potencialidades geradoras de mudanças. Os PMC afiguram-se, por isso, como dispositivos de intervenção de melhoria (como processo de inovação e não tanto como situação final a alcançar).

O PMC em estudo assenta em quatro vertentes: a) técnica de intervenção na gestão e resolução de conflitos; b) metodologia integrada de prevenção: primária, secundária e terciária; c) ferramenta de desenvolvimento pessoal e social; d) estratégia de melhoria. Dadas as exigências inerentes à implementação dos PMC, requerem-se mudanças, tanto a nível interpessoal, como a nível organizacional. Trata-se de uma intervenção em que indivíduos e organização apre(e)ndem novos procedimentos, usufruem de novas estruturas e beneficiam de processos promotores de qualidade socioeducativa (Pinto da Costa, Torrego \& Martins, 2017).

Os PMC integram-se entre duas principais tipologias de acordo com a sua amplitude (cadre programs ou whole programs). O modelo de PMC de amplo alcance foi defendido por vários autores, que reconheceram as limitações dos programas de mediação entre pares. Jones (2002) propõe um "whole program", com as seguintes áreas: mediação entre pares, formação adicional de alunos, formação adicional dos restantes elementos da comunidade educativa, inclusão curricular, envolvimento da escola toda. Alzate (2003) apresenta um projeto de "enfoque global", integrando as seguintes dimensões: sistema disciplinar, currículo, pedagogia, cultura escolar e comunidade. Torrego (2006) concebe um "modelo integrado de gestão da convivência" que compreende, necessariamente, três principais áreas: gestão das normas de convivência 
e disciplina, orgânica-funcional e orgânica-curricular, propondo também a articulação entre modelo impositivo e modelo relacional; Faget (2010) advoga, também, a "whole approach" que congrega a mediação entre pares, pelos adultos, escola-família e a mediação restaurativa. As finalidades que subjazem a estas propostas de intervenção de mediação de amplo espectro consistem em permitir que a escola proporcione aos seus alunos aprendizagens significativas, promova competências sociais e fomente contextos favoráveis à formação pessoal e à vivência social.

As investigações recentes acerca dos PMC têm incidido na pesquisa de certas variáveis e perspetivas, das quais se podem destacar: aquelas que atendem às aprendizagens dos sujeitos implicados no projeto, desde o ensino básico (Akgun \& Araz, 2014) ao ensino secundário (García-Longoria \& Vázquez, 2013), destacando as aprendizagens cognitivas, emocionais e morais (Halperin \& Gross, 2011, Ibarrola-García \& Iriarte, 2014a, Ibarrola-García, Iriarte \& Aznárez-Sanado, 2017). Outros estudos revelam a eficácia de programas de formação em mediação de professores (Torremorell \& García, 2010). Outros ainda mostram os benefícios, a dinâmica, as estruturas e o impacto dos PMC, na perspetiva dos alunos e professores (Silva \& Torrego, 2017, Ibarrola-García e Iriarte, 2014b, Grau, García-Raga \& López-Martín, 2016), assim como sobre os fenómenos perturbadores da convivência escolar, caso da violência entre pares (Ortega-Ruiz, Del Rey \& Casas, 2016) e no que se refere ao clima social de escola (Peñalva-Vélez, López-Goñi, Vega-Osés \& Satrústegui-Azpíroz, 2015).

Face ao ponto de situação da investigação estrangeira, também em Portugal são precisas investigações mais aprofundadas, que convençam a comunidade científica e a escola da utilidade deste tipo de projetos.

\section{Metodologia}

\subsection{Objetivos}

Na senda da construção de um esquema de análise interpretativa estabeleceram-se dois objetivos, interrelacionados com a dimensão de análise do PMC: i) analisar o impacto da intervenção naqueles que participam no projeto; ii) indagar os efeitos e benefícios do projeto nas relações interpessoais e na convivência escolar. Associado a esses objetivos definiram-se duas questões norteadoras: i) em que medida o projeto permite a promoção de habilidades na gestão das relações interpessoais e dos conflitos? e ii) qual o impacto do projeto na melhoria relacional e social da escola? Nestes objetivos e questões evidencia-se a opção pelo estudo qualitativo, assente em processos compreensivos da realidade em análise e em avaliação, através das representações, dos significados, das crenças e das práticas em torno do PMC. 


\subsection{Participantes}

O número de participantes na investigação foi-se ajustando à evolução do estudo, para completar ou contrastar os dados recolhidos e em função da natureza do projeto de investigação - intervenção. Assim, na fase mais adiantada do projeto realizaram-se três entrevistas. Especificamente, entrevistaram-se dois professores mediadores, sendo um coordenador do programa TEIP (CPTEIP) e outro coordenador da equipa de mediação (CEM). Ambos os professores acompanharam o PMC desde o início, apresentando um envolvimento com a mediação de cerca de cinco anos. Entrevistou-se também um grupo de dez alunos, na modalidade de Entrevista de Grupo Focal. A seleção foi feita de acordo com quatro critérios: i) ligação ao projeto como mediadores; ii) disponibilidade pessoal; iii) diferença de tempo de participação no projeto; iv) consenso entre a coordenadora da equipa de mediação e a investigadora. Assim, os alunos participantes tinham idades compreendidas entre os 12 e os 15 anos, distribuídos da seguinte forma: 1 com 11 anos, 4 com 13 anos, 4 com 14 anos e 1 com 15 anos. Um dos alunos frequentava o segundo ciclo e 9 frequentavam o terceiro ciclo do ensino regular $(n=7)$ e do ensino vocacional $(n=2)$. Os jovens distinguiam-se pelo número de anos como mediadores: 4 com 3 anos, 5 com 4 anos, 1 com 1 semana. Nessa seleção atendeu-se então aos critérios de uniformidade (perfil) e de diversidade (idade, sexo e anos de participação no projeto), numa relação de equilíbrio (Galego \& Gomes, 2005).

\subsection{Método e procedimento}

A entrevista foi a opção metodológica para obter informação para a pesquisa. Em conformidade com a natureza semiestruturada da entrevista adotada, o guião elaborado para entrevistar os professores compreendeu três categorias de perguntas: i) perguntas abertas, ii) perguntas impulsionadas pela teoria e/ou orientadas pelas dimensões e subdimensões e iii) perguntas confrontativas. Desta forma, o investigador visa aceder à perceção matizada dos discursos dos entrevistados. Já na Entrevista de Grupo Focal com os alunos mediadores, o investigador observa a espontaneidade em relação ao tópico discutido e envolve-se na determinação e na manutenção desse tópico em discussão. Este tipo de entrevista está associado à riqueza de informação que a interação dos elementos do grupo pode proporcionar por comparação à entrevista individual, o que foi potenciado através de um guião igualmente adaptado a uma entrevista semiestruturada. Foi também elaborado, ao longo do procedimento da análise de conteúdo, um mapa das áreas temáticas e um sistema de categorias, prévias e emergentes (Amado \& Ferreira 2013). Em suma, o recurso às entrevistas aos indivíduos selecionados proporcionou uma multiplicidade de informação qualitativa sobre o PMC. 


\section{Análise e discussão dos resultados}

\subsection{Apropriação de habilidades e desenvolvimento pessoal}

$\mathrm{Na}$ categoria de análise "aquisição de habilidades", denotou-se nos discursos dos dois professores, na mesma linha do estudo de Ibarrola-García, Iriarte e Aznárez-Sanado (2017), uma mudança no relacionamento com os alunos, conseguindo uma melhor satisfação em relação a necessidades pessoais e profissionais:

"Inclusivamente no meu trabalho de diretora de turma, a forma como eu perceciono as questões, e as próprias respostas e os pedidos que ia fazendo aos meninos (...)" (CEM). "(...) eu aqui tento ser uma pessoa diferente com eles" (CPTEIP).

A mudança de postura, mencionada por Ibarrola-García e Iriarte (2014a), foi, todavia, mais notória entre aqueles professores que tiveram oportunidade de colaborar no gabinete de mediação, corroborando assim os benefícios da aprendizagem experiencial, pois estes tendem a tornar-se mais aptos na gestão dos conflitos e mais resilientes na forma como lidam com os problemas, como também apontam Torremorell e García (2010).

"Os [professores da equipa] que têm formação são mais confiantes, mais tranquilos. (...)" (CPTEIP). "(...) quem está mais diretamente relacionado com o gabinete (de mediação) ou teve a oportunidade de passar pelo gabinete, tem essa mais valia e admite-o sempre. (...)" (CPTEIP).

Esta metodologia de encarar o conflito acabou por seduzir os restantes professores: "Numa espécie de osmose. Sim, sim. Para já com o convívio com professores que são professores mediadores. Sobretudo perguntam muito como é que funciona, como é que é e depois..." (CPTEIP). Ora, corroborando a tese de Ibarrola-García e Iriarte (2014a), a existência de figuras e estruturas de mediação pode induzir nos restantes professores a predisposição para concretizar outras abordagens na gestão de problemas de comportamento na sala de aula.

Na perspetiva do professor coordenador do programa TEIP, a promoção de habilidades de mediação foi mais reduzida nos assistentes operacionais.

"Sinto que os funcionários estão mais distantes nessa perceção das coisas

(...) isso porque não se apropriaram das técnicas certas, não se muniram dessa ferramenta. (...)" (CPTEIP). 
Em relação aos alunos mediadores, os professores entrevistados reconheceram ter havido mudança. Estes "(...) já dominam o conceito! Eles já percebem. É diferente porque ouviam falar e estiveram envolvidos (...)" (CEM). Essa mudança resulta das aprendizagens adquiridas: "(...) Os que tiveram formação, sim. Esses ficam com outra sensibilidade. É diferente, falarmos para um aluno que teve, ou uma turma que teve formação e uma turma nova" (CPTEIP). Da análise dos discursos constaram as seguintes características dos alunos mediadores: i) uma atitude de atenção e de comprometimento: "O que eu vejo é o interesse e a importância que eles dão. E acho que quando eles me interpelam, "ó professora isto é um caso para mediação". É porque ficou lá alguma coisa! Eles reconhecem que a mediação ajuda" (CEM); ii) uma postura de intervenção: "Eu sei que alguns faziam mediações informais, até porque, "ó professora, já ajudei"; "ó professora vou ali ajudar um colega a resolver um conflito". (CEM); iii) uma atuação preventiva de situações mais graves: "E temos alunos, que (...) conseguiram evitar uma situação de conflito, porque, entretanto, tomaram as rédeas da situação e puseram os colegas a conversar." (CPTEIP). Em síntese, o comprometimento dos jovens, com os seus pares e o seu contexto, é uma marca caraterística dos alunos mediadores: "(...) eles envolvem-se muito (...)" (CEM). Esta mudança surge confirmada em outros estudos sobre as aprendizagens adquiridas pelos alunos mediadores (García-Longoria \& Vázquez, 2013) e o desenvolvimento da competência emocional, bem como sociocognitiva e sociomoral (Ibarrola-García \& Iriarte, 2014b).

A associação das competências entre a aprendizagem adquirida pela mediação e o crescimento pessoal foi evidenciada pelos alunos mediadores entrevistados. Quatro desses alunos apontaram quatro principais mudanças pessoais: i) maior consciencialização na atuação com os colegas: "(...) depois da formação nós chegamos à conclusão que a maneira como nós atuávamos não era a mais correta e se calhar estava na altura de (...) começarmos a resolver as coisas de forma mais correta" (EGAMdor5); ii) mais autoconfiança: "Depois da formação dá aquela: ok, quero ser mediadora, eu vou utilizar isto" (EGAMdor10); iii) mais autocontrolo: "(...) depois de fazer a formação percebi que consegui começar a falar mais com ele, a resolver melhor as coisas. Às vezes ainda expludo, mas não tanto como explodia" (EGAMdor6); iv) mais empatia: "Acho que sim, mudou. Também a perceção que eu tenho das pessoas (...) mudou a forma de eu chamá-las à razão" (EGAMdor2).

Em resumo, constatou-se que a aprendizagem das habilidades de mediação contribuiu para uma melhoria na forma como professores e alunos mediadores se relacionavam com os demais, percecionando um crescimento pessoal.

\subsection{Da perceção ao reconhecimento e à ação do mediador}

A análise de conteúdo da Entrevista de Grupo Focal revelou seis caraterísticas basilares do mediador: i) ter capacidade de intervir; ii) gostar de ajudar; iii) ter bons 
relacionamentos; iv) ser isento; v) ter aptidão e vi) querer sê-lo. Destas várias características, a primeira obteve maior número de ocorrências. Os alunos mediadores entrevistados evidenciaram que ser mediador é atuar, devendo para isso saber fazê-lo com coragem:

"Saber agir perante uma situação" (EGAMdor6), "Mesmo com medo, saber agir. (...)". (EGAMdor5), "(...) ser mediador é preciso ter coragem para poder intervir nos problemas (...)" (EGAMdor2), "Coragem" (EGAMdor6), "(...) Até mesmo ter medo de te poderem aleijar a ti próprio ou de piorares a situação. Precisamos de ter coragem, não é?" (EGAMdor2).

A segunda característica reuniu consenso entre dois alunos mediadores:

"(...) o papel do mediador também pode servir para ajudar essas pessoas" (EGAMdor8), "Ser mediador é ajudar as outras pessoas" (EGAMdor5), "Gostar de ajudar os outros" (EGAMdor8).

Os alunos entrevistados revelaram também ser importante o mediador ter bons relacionamentos interpessoais: "(...) ter melhores relações com as pessoas" (EGAMdor2); ser isento: "não é por ir pelo nosso amigo que somos melhores mediadores. Convém que nós vejamos a realidade e não aquilo que nós queremos que seja" (EGAMdor5); ter aptidão e ter vontade de sê-lo: "É ter aquele dom!" (EGAMdor10). "Querer, a vontade." (EGAMdor5).

As caraterísticas do mediador refletem uma forma de estar na escola implicada nos valores da solidariedade, do companheirismo e de cidadania. Os alunos mediadores desenvolveram a confiança, a responsabilidade e o comprometimento enquanto cidadão atuante no seu contexto.

São os professores entrevistados que confirmam a avaliação positiva da intervenção dos alunos mediadores na escola.

"É um estatuto importante" (...). "eles sentem-se orgulhosos" (...) "eles ficam vaidosos." (...) "eles realmente envolvem-se e mostram que gostam de ser mediadores. "(...) "vêm reportar situações em que eles foram autênticos heróis (...) nas turmas dos mais velhinhos, que já têm outra maturidade, isso começa a ter um peso importante (...)" (CPTEIP). "Eles gostam" (CEM).

Aliás, segundo um dos professores, os alunos mediadores reclamam o seu reconhecimento institucional: "Então professor e os mediadores? Onde é que fica escrito 
aí no livro?" (...) "então, os alunos da mediação não estão aqui?" (CPTEIP). Reconhece-se que os alunos mediadores são influenciados pela autoidentificação com o perfil do mediador.

No que se refere ao professor mediador, identificou-se também uma perceção positiva, aceitação e reconhecimento:

"Quem está no gabinete (...) está de corpo e alma" (...) "Há uma boa aceitação, ainda bem que vocês cá estão!" (...) "já tenho um caso para si, dizem isto muitas vezes" (...) "vêm por eles próprios" (...) "O senhor l, que é um funcionário, foi ele que Ihe disse, era bom o seu filho ir à mediação"

(...) "A diretora de turma é que me veio dizer: olha, falaste com o J e a mãe ficou muito contente" (CEM).

Todavia, os alunos entrevistados frisaram existir pouca confiança na sua atuação, seja por parte dos professores: "Não nos chamam para atuar" (EGAMdor6). "(...) [os professores] nem sempre têm confiança em nós para fazer aquilo que eles podem fazer. (...)" (EGAMdor8), seja por parte dos assistentes operacionais: "(...) algumas preferem ser elas a resolver por serem mais velhas" (EGAMdor5). "(...) é aquela coisa de pensarem que como são mais velhas vão conseguir resolver o problema (...)" (EGAMdor7).

Em suma, constatou-se uma perceção positiva do perfil do mediador, apesar da necessidade de mais afirmação da ação do aluno mediador em contexto.

A mediação implica uma ação que não se concretiza sem dificuldades. O PMC serve, por isso, como quadro protetor de uma nova forma de ser e de estar na escola, que contribui para a (re)atualização de valores pró-sociais.

\subsection{A promoção do clima relacional e social escolar}

No decurso do projeto, em funcionamento desde 2009, constatou-se que era ainda difícil para os professores entrevistados avaliar se a mediação tinha tido impacto no clima social escolar: "Não posso ainda afirmar" (CEM). "(..) Não tenho dados para precisar isso (...)" (CPTEIP). Todavia, havia uma perceção de melhoria das relações interpessoais. Este é um resultado central da dimensão educativa e preventiva dos PMC, como evidenciam Halperin e Gross (2011). Como referiu a coordenadora da equipa: "(...) as relações têm vindo a melhorar" (CEM), e, segundo o coordenador do TEIP, assistiu-se também ao efeito do gabinete de mediação na melhoria dos relacionamentos entre alunos e entre alunos e professores na prevenção de situações de rutura.

"(...) eu vejo o respeito por passarem a cumprimentar quando me veem na escola (...). Fazem até questão" (CPTEIP). "(...) alguns dos alunos 
Costa, Torrego \& Martins: Mediação escolar um projeto de intervenção numa escola TEIP

depois de passarem pelo gabinete e de terem hipótese de conversar, de resolver o seu conflito, tornam-se alunos mais meigos, mais respeitadores e isso acontece especialmente em relação aos professores que estiveram envolvidos na mediação" (CPTEIP). "Os diretores de turma (...) dizem: "Olha, que ele está mais calmo". "Já não anda sempre às turras com a colega (...)" (CPTEIP).

Em específico, na relação entre professor e aluno, o coordenador do TEIP destacou uma lógica de respeito:

“(...) primeiro os alunos respeitam a mediação e respeitar a mediação implica também respeitar os professores mediadores. Havendo ou não acordo, não interessa, eles vêm sempre o professor, como o professor do gabinete de mediação. (...) E de maneira que a relação com esses alunos, que muitas vezes não conheço, é de respeito" (CPTEIP).

Um dos alunos mediadores mencionou também que a mediação facilitava os relacionamentos e promovia amizades:

"Inclusivamente quando nós resolvemos um conflito, por exemplo: há duas raparigas que não se dão nada bem. Depois quando tentamos interferir no conflito, as raparigas até passam a ser amigas e a conhecerem-se melhor e a perceberem que afinal têm (...) uma grande amizade. Isso acontece muito" (EGAMdor8).

As sessões de mediação eram, na opinião dos alunos entrevistados, favoráveis à promoção do ambiente escolar: "Normalmente é sempre bem-sucedida" (EGAMdor5). "Tem um efeito positivo, depois" (EGAMdor4). Em sintonia, o coordenador do TEIP referiu-se aos efeitos das mediações formais da seguinte forma: "Curiosamente, funciona um pouco como um tranquilizante (...)" (CPTEIP). Denotaram-se melhorias de comportamento: "Olha, falei com a mãe do aluno x e ela está a notar um comportamento diferente do filho, depois de ter feito o processo de mediação (...)" (CPTEIP), e de predisposição para abordar os conflitos de forma pacífica:

"Depois quando nos encontram no recreio: "ó professora eu não me esqueci!", "ó professora, está a resultar!", ou o inverso: "ó professora, então ele não está a fazer nada daquilo!" Está bem, precisas de voltar, voltas lá. (...)" (CEM). 
Com estes registos constatou-se que a mediação contribuiu para melhorar o ambiente relacional na escola e, consequentemente, para um clima social positivo.

Os alunos mediadores entrevistados sustentaram uma apreciação favorável da mediação sobre as relações interpessoais, graças aos efeitos que esta exerce sobre os alunos envolvidos, mas também à germinação de uma lógica de apoio e de entreajuda, decorrente da ação dos mediadores na construção de pontes de comunicação e de entendimento. Nos discursos analisados destacaram-se as seguintes referências: i) a influência positiva dos mediadores, como pacificadores: "As pessoas começam a falar. Começam, depois da nossa atuação. Cada vez que têm um conflito têm aquela intuição de nos procurar (...)" (EGAMdor5); ii) as vantagens da mediação como um meio menos desgastante para resolver conflitos: "(...) depois da primeira mediação já se começa a procurar mediadores, já sabem que é muito mais fácil e rápido" (EGAMdor4); iii) a confiança entre os alunos gerada pela mediação: "Sentem-se seguros e confiantes quando nós ajudamos. Sabem com quem podem contar, porque nós estamos aqui é para ajudar as outras pessoas" (EGAMdor8); iv) a mediação permite recuperar amizades quebradas: "(...) por norma acabaram bem. As pessoas ficam amigas" (EGAMdor6). Anteviu-se, assim, destes discursos uma forma positiva de interação social, não adversarial, que se foi afirmando na escola por força da presença de alunos e professores mediadores.

Encarada como um elemento perturbador da convivialidade e do processo de ensino e aprendizagem, a indisciplina constituiu para o coordenador do TEIP uma área fundamental para o sucesso da mediação na melhoria do clima escolar:

"E nós temos diminuído as situações de indisciplina, em parte, também pela atuação do gabinete de mediação (...)" (CPTEIP). "(...) muitos dos casos que nós aqui conseguimos resolver em termos de mediação, quer formal, quer informal, se não houvesse gabinete, podiam ter disparado as situações de indisciplina (...)" (CPTEIP).

Neste estudo, a indisciplina assumiu-se como um dos principais fatores justificativos da adoção do PMC. O coordenador do TEIP, mais ciente institucionalmente das necessidades e da avaliação da escola, reforçou a perceção positiva dos efeitos do projeto numa perspetiva preventiva, ao afirmar que:

\footnotetext{
"Houve uma alteração para melhor. E ela tem resultados concretos que é nas situações depois a montante, de indisciplina, que são menores, têm vindo a reduzir gradualmente e é consensual saber que o gabinete de mediação tem um papel nisto. (...). As pessoas sabem qual o trabalho feito pelo gabinete (...)." (CPTEIP).
} 
Em suma, a mediação oferece à escola e aos indivíduos novas formas de relacionamento que fortalecem, dia a dia, um clima de sã convivência, pela prevenção do conflito, da indisciplina e da violência.

\section{Conclusão}

Sobre a dimensão interpessoal e social do PMC implementado numa escola TEIP, segundo uma abordagem metodológica qualitativa, intentou-se perceber como o projeto influiu na relação entre os indivíduos, nos indivíduos per si e no ambiente relacional e social escolar.

Em jeito de conclusão, propõe-se seguir as questões norteadoras identificadas no início deste artigo. Assim, sobre a promoção de habilidades na gestão dos conflitos e das relações interpessoais, verificou-se que os professores desenvolveram uma forma mais atenta, mais confiante, mais tranquila, mais empática e educativa de tratamento dos conflitos. Reconheceu-se também que a capacitação não se verificou de maneira idêntica em todos os professores e alunos. Por exemplo, somente os professores que passaram pelo gabinete de mediação tiveram oportunidade de consolidar as aprendizagens, exercitar as técnicas e confiar nos resultados da aplicação do método. Os alunos demonstraram uma forma construtiva de estar perante as controvérsias, dominando o conceito de mediação e apresentando-se bastante interventivos na gestão dos conflitos. Depreendeu-se também da análise que professores, assistentes operacionais e alunos (com formação em mediação e com pouco ou nenhum envolvimento na prática da mediação) um menor domínio das aprendizagens. Por isso, inferiu-se que a formação deveria ser reforçada e beneficiada com a participação nas estruturas de mediação, de forma a melhorar o desempenho dos alunos e dos professores mediadores. Também se tornara diferente abordar os conflitos em turmas que tinham tido sensibilização ou formação em mediação.

A valorização que o estatuto do mediador granjeou junto dos professores e dos alunos entrevistados foi unânime. Estes reconheceram tratar-se de uma missão e, especialmente, de uma forma de estar na escola. Em específico, no caso dos alunos entrevistados reconheceu-se um efeito positivo em termos de autoestima pessoal e relacional, embora o reconhecimento das suas capacidades, por parte de alguns adultos, nem sempre ocorra. Com efeito, verificou-se que a figura do aluno mediador impôs-se, sobretudo, pelo seu significado. Conscientes da relevância do seu papel, os alunos mediadores assumiram-se como embaixadores da mediação na escola.

Por fim, reconheceu-se o contributo do projeto para a melhoria do clima social da escola. Tanto as estruturas de mediação como os mediadores passaram a exercer uma ação positiva no seu contexto, colocando em prática mecanismos de qualificação das relações interpessoais. A metodologia da mediação proporcionou o restabelecimento 
de pontes de diálogo e de entendimento entre alunos, a resolução de situações problemáticas ocorridas na sala de aula e a aquisição de uma postura proactiva e positiva de abordagem aos conflitos e às relações interpessoais. Contudo, estas constatações não permitiram atestar que a cultura de escola tenha sido invadida pela cultura de mediação. Presenciou-se uma manifestação de cultura de escola, no que respeita à mediação, entre o tipo diferenciadora (uma tendência para) e o tipo integradora (Torres, 2014), porque constatou-se um elevado grau de partilha de valores, costumes, rotinas e rituais, no seio do grupo de participantes no projeto e, especialmente, nos participantes no estudo. Resta esperar que a cultura de escola e a cultura de mediação continuem a mesclar-se para apresentar um grau mais elevado e generalizado de partilha e de identificação pelos sujeitos e pela organização. Em todo o caso, o PMC contribuiu para edificar as bases para a emergência da cultura de mediação, em virtude da sua gradual (e ainda difícil) afirmação nos âmbitos interpessoal e social. Em síntese, o PMC revelou-se um meio essencial para a promoção de valores, princípios, dispositivos e atitudes de uma convivência sã, colaborativa e de cidadania.

\section{Referências Bibliográficas}

Alzate, R. (2003). Resolución de conflictos. Transformación de la escuela. In E. Vinyamata (Coord.), Aprender del conflicto. Conflicto e educación (pp. 51-64). Barcelona: Graó.

Amado, J. \& Ferreira, S. (2013). A entrevista na investigação educacional. In J. Amado (Coord.), Manual de Investigação Qualitativa em Educação (pp. 207-233). Coimbra: Imprensa da Universidade de Coimbra.

Bonafé-Schmitt, J.-P. (2014). Les médiations scolaires en France. État des lieux. Diversité, 175, 42-47.

Akgun, S. \& Araz, A. (2014). The effects of conflict resolution education on conflict resolution skills, social competence, and aggression in Turkish elementar school students. Journal of Peace Education, 11(1), 30-45.

Faget, J. (2010). Médiations. Les ateliers silencieux de la démocratie. Toulouse: Érès.

García-Longoria, M. \& Vázquez, R. (2013). La mediación escolar y las habilidades sociales en los estudiantes de educación secundaria. Un estudio en institutos de la región de Murcia. Comunitania: Revista Internacional de Trabajo Social y Ciencias Sociales, 5, 114-137.

Grau, R., García-Raga, L. \& López-Martín, R. (2016). Towards school transformation. Evaluation of a coexistence program from the voice of students and teachers. Journal of New Approaches in Educational Research, 5(2), 137-146.

Halperin, E. \& Gross, J. (2011). Emotion regulation in violent conflict: reappraisal, hope, and support for humanitarian aid to the opponent in wartime. Cognition y Emotion, 25, 1228-1236.

Ibarrola-García, S. \& Iriarte, C. (2014a). La influencia positiva de la mediación escolar en la mejora de la calidad docente e institucional: percepciones del profesor mediador. Profesorado. Revista de Currículum y Formación del Profesorado, 17(1), 367-384. 
Ibarrola-García, S. \& Iriarte, C. (2014b). Desarrollo de las competencias emocional y sociomoral a través de la mediación escolar entre iguales en educación secundaria. Revista Currículum, 27, 9-27.

Ibarrola-García, S; Iriarte, C. \& Aznárez-Sanado, M. (2017). Aprendizaje emocional autoconsciente durante procedimientos de mediación en el contexto escolar. Electronic Journal of Research in Educational Psychology, 15(1), 75-105.

Jones, T. (2002). School conflict management. Evaluating your conflict resolution education program. Ohio: Commission on Dispute Resolution and Conflict Management.

Ortega-Ruiz, R., Del Rey, R., \& Casas, J. (2016). La Convivencia Escolar: clave en la predicción del Bullying. Revista Iberoamericana de Evaluación Educativa, 6(2), 91-102.

Peñalva-Vélez, A., López-Goñi, J., Vega-Osés, A., \& Satrústegui-Azpíroz, C. (2015). Clima escolar y percepciones del profesorado tras la implementación de un programa de convivencia escolar. Estudios sobre Educación, 28, 9-28.

Pinto da Costa, E. \& Barandela, T. (2010). A mediação escolar na narrativa dos alunos do ensino secundário. In L. Almeida, B. Silva, S. Caires (Eds.), Atas do / Seminário Internacional Contributos da Psicologia em Contextos Educativos (pp. 1354-1368). Braga: Universidade do Minho.

Pinto da Costa, E. (2010). Novos espaços de intervenção: a mediação de conflitos em contexto escolar. In J. Vasconcelos-Sousa (Coord.), Mediação e criação de consensos: os novos instrumentos de empoderamento do cidadão na União Europeia (pp. 155-166). Coimbra: Mediarcom/Minerva.

Pinto da Costa, E., Torrego, J., \& Martins, A. (2017). A investigação qualitativa como metodologia compreensiva da dimensão interpessoal/social de um projeto de mediação de conflitos. In A. P. Costa, S. Tuzzo, \& C. Brandão (Eds.), Atas do $6^{\circ}$ Congresso Ibero-Americano em Investigação Qualitativa Volume 1 - Investigação Qualitativa em Educação (pp. 683-691). Oliveira de Azeméis Aveiro - Portugal: Ludomedia.

Quaresma, L. (2010). Interação e indisciplina na escola. In P. Abrantes (Org.), Tendências e controvérsias em sociologia da educação (pp. 159-171). Lisboa: Mundos Sociais.

Silva, I., \& Torrego, J. (2017). Percepción del alumnado y profesorado sobre un programa de mediación entre iguales. Qualitative Research in Education, 6(2), 214-238.

Torrego, J. (2006). Modelo integrado de mejora de la convivencia. Estrategias de mediación y tratamiento de conflictos. Barcelona: Graó.

Torremorell, C. \& García, L. (2010). Evaluación diferida de la formación del profesorado en convivencia y mediación. REIFOP, 13(3), 87-94.

Torres, L. (2014). A ritualização da distinção académica. O efeito cultura de escola. In L. Torres \& J. Palhares (Orgs.), Entre mais e melhor escola em democracia. Inclusão e excelência no sistema educativo português (pp. 33-56). Lisboa: Editora Mundos Sociais, CIES, ISCTE-IUL. 
Elisabete Pinto da Costa

Universidade Lusófona do Porto e CeiED - Centro de Estudos

Interdisciplinares em Educação e Desenvolvimento

Porto, Portugal

Email: elisabete.pinto.costa@ulp.pt

ORCID: 0000-0002-6255-4135

Juan Carlos Torrego Seijo

Faculdade de Educação da Universidade de Alcalá

Alcalá de Hernares, Espanha

Email: juancarlos.torrego@uah.es

ORCID: 0000-0003-2072-1959

Alcina Manuela de Oliveira Martins

Universidade Lusófona do Porto e CeiED - Centro de Estudos

Interdisciplinares em Educação e Desenvolvimento

Porto, Portugal

Email: amom@ulp.pt

ORCID: 0000-0002-0290-747X

Data de submissão: Março de 2017

Data de avaliação: Abril de 2017

Data de publicação: Julho 2018 